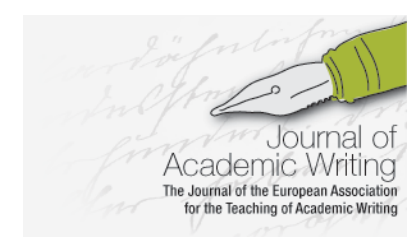

Journal of Academic Writing

Vol. 10 No 1 WINTER 2020, pages 180-187 https://doi.org/10.18552/joaw.v10i1.618

\title{
Building Bridges: The Effective Learning Adviser as Transcultural and Cross-Disciplinary Communicator
}

\author{
Julia Bohlmann \\ University of Glasgow, Scotland, UK
}

\begin{abstract}
Out of 31,060 students currently enrolled at the University of Glasgow, about $25 \%$ are classed as international, reflecting a nationwide trend. In response to this situation, researchers and practitioners have stressed the need to improve the way universities accommodate multicultural student bodies. At the University of Glasgow, such efforts manifest in an expansion and diversification of the department facilitating student learning development: The Learning Enhancement and Academic Development Service (LEADS). LEADS is home to two Effective Learning Advisers (ELAs) who work with international students from all subject disciplines. Their work entails the creation and delivery of academic writing classes, the development of electronic resources and one-to-one tutorials. Due to the diversity of the international student cohort in terms of educational, cultural and subject backgrounds, a significant proportion of the international ELAs' day-to-day job is to explain generic academic writing conventions pertinent to the UK Higher Education context to those coming from other educational cultures. Their role then is that of multicultural and cross-disciplinary communicators. This article outlines and reflects on the professional practice of the international ELAs and seeks to stimulate discussion around appropriate and effective practices of teaching academic writing to students from a multiplicity of backgrounds and disciplines.
\end{abstract}

\section{Introduction}

Out of 31,060 students currently enrolled at the University of Glasgow (UofG), 7,686 are classed as international, making up ca. $25 \%$ of the overall student population (University of Glasgow, 2019). This reflects a national trend: During the 2018-19 academic term, ca. $20 \%$ of the UK's student population was made up of international students, with numbers likely to increase (Higher Education Statistics Agency [HESA], 2020). In response to this trend, researchers and practitioners have stressed the need to improve the way universities accommodate multicultural student bodies, with adjustments being made sector wide as well as on the institutional level (Ryan, 2011; Jindal-Snape et al., 2016; Quality Assurance Agency [QAA] Scotland, 2017; Merola et al., 2019). UofG's current efforts of adjustment focus mainly on two areas: supporting student transitions and internationalising the curriculum, with the latter taking longer to implement. Specifically, the institution seeks to create "learning experiences that are culturally accessible to all" and aid transition of international students through "effective and evidencebased interventions" (University of Glasgow, 2015, p. 5). One such intervention is the expansion and diversification of the department facilitating student learning development: the Learning Enhancement and Academic Development Service (LEADS). Positioned centrally in university services, LEADS is home to four Effective Learning Advisers (ELAs) who provide subjectfocused advice and two ELAs who work specifically with international students from all subject disciplines (Fig. 1). International students have access to both types of advice throughout the whole academic year. The ELAs create and deliver mostly optional academic writing classes, develop electronic resources for online learning and hold one-to-one tutorials with students. Outside of LEADS, international students have access to the English for Academic Study unit 
for pre- and in-sessional language training, and those enrolled in Social Sciences degrees are also supported by two international student learning officers based in the College of Social Sciences.

\section{Figure 1}

\section{LEADS in University Services}

2 ELAs International Students - advise international students in all subjects

ELA College of Arts - advises all students in arts subjects Engineering - advises all students in science subjects
ELA College of Science and
ELA College of Social

Sciences - advises all students in social science subjects (College with most international students)

ELA College of MVLS advises all students in medical subjects

The key challenges in achieving accessibility for and inclusivity of international students have been identified as language barriers, a lack of social and cultural integration, and a disparity of academic expectations between academic staff and students (QAA Scotland, 2017). At UofG, the first two challenges are addressed by the English for Academic Studies unit and other academic and professional departments. The international ELAs, on the other hand, seek to bring about a better alignment of expectations by assisting students to bridge the divide between their home academic culture and UK academic culture. A significant proportion of the ELAs' day-to-day job is to introduce international students to academic writing conventions pertinent in the UK and clarify what this means in practice when they approach academic assessments. While student development is important, this paper acknowledges that it cannot be the only way to address the challenge of creating a more inclusive and accessible learning environment. As Ryan (2011) argued, a transcultural approach is required to achieve that, an approach that expects adjustment not just from international students but also from the academic institutions hosting them. In particular, she stated that such an approach should examine "the cultural origins of contemporary academic practices" and "review them" (p. 644). Although the international ELAs do not themselves cross academic cultures as envisaged by Ryan, this paper argues that they play a crucial role in building bridges for students to do so. They achieve this by being explicit about what is characteristic about UK academic culture and acknowledging diverging experiences and expectations. Bound by institutional structures, the international ELAs must also adopt a cross-disciplinary approach that engages international students from all subject disciplines. In order to communicate successfully across disciplines, the ELAs need an understanding of "how knowledge in [each] discipline is presented, debated and constructed" (Wingate \& Tribble, 2012, p. 482), representing one of the principal challenges of their work.

With a view of demonstrating the complexity of the international ELA role, the article outlines and reflects on their professional practice at UofG. It focuses on three key areas making up the provision offered to international students: open access classes, complementary online 
resources and one-to-one advice. Its objective is to stimulate discussion around appropriate and effective practices of teaching academic writing to students from a multiplicity of backgrounds and disciplines.

\section{Early Interventions - Start up programme}

The international ELAs offer classes throughout the academic year. Most of these focus on academic writing skills and a smaller number on other academic skills, such as research skills or exam revision strategies. The classes are optional, non-credit bearing and open to international students from all subject areas. This means that the ELAs have to engage a cohort of students whose academic skills and expectations are extremely wide ranging. Timing and selection of relevant topics is crucial in order to retain the appeal of these classes as they are chosen on top of compulsory modules in the respective subject areas. Hence, the international ELAs start their classes before the first semester has officially begun. They do so to create a smooth transition for those students who have spent the summer months attending presessional courses at UofG and those who are on campus after police registration, awaiting their courses to start. Subject courses typically start in the second semester week when all induction events have taken place, enabling students to attend the preparatory classes offered. The ELAs commence the international classes with lectures that up to 150 students attend; these are repeated two to three times to suit varying timetables. The topics selected for these lectures are Writing as an International student at UofG; Becoming an Academic Reader; Ownership of Knowledge and Criticality in Reading and Writing. They echo the key themes the ELAs see international students encounter when enrolling in a degree at UofG and set the tone for smaller workshops delving deeper into these topics as follow-up options.

One such key theme is plagiarism and how to avoid it. Students' engagement with the topic tends to be narrow, with questions frequently focusing on how not to be caught, technicalities of referencing, or procedures and penalties should they be accused of plagiarising. This limited focus on the legal discourse around plagiarism has been confirmed in small scale research in Denmark (Jensen \& Bay, 2019). To some extent, the focus has been facilitated by the sector itself with academics and commentators typically using words such as "cheating", "detecting", "academic misconduct" and similar terms when discussing the topic and the widespread use of so-called plagiarism checking software (Grove, 2014: QAA Scotland, 2017; McKie, 2019). The tendency among academic staff, especially those teaching international students, is to warn, not to educate about plagiarism, priming students' narrow engagement with the topic rather than facilitating a more in-depth understanding. Staff concern is not groundless, of course. Speakers of English as a second language have been found to plagiarise more than other student demographics, with lacking language proficiency, cultural differences in academic practice, and a non-alignment of academic expectations being cited as reasons (Pecorari, 2008; Mostrous \& Kenber, 2016). Unsurprisingly, the reasons are the same as those identified to hinder international students' successful transition (QAA Scotland, 2017). As Pecorari (2008) recommends, if any meaningful integration of international students is to be achieved, the solution to the problem of plagiarism must be pedagogical rather than punitive. The international ELAs at UofG, therefore, attempt to facilitate a broader debate about the context and significance of ownership of knowledge, a debate that requires reflection on the cultural origins of plagiarism as a concept. Such reflection moves away from the practice of only talking about rules and penalties - though this is undoubtedly necessary - towards a communication and translation of culturally specific academic expectations that help students to fully grasp the issue. Hence, the ELAs introduce plagiarism as a concept that has developed in association with the idea and institutionalisation of intellectual ownership before outlining the rules resulting from it.

One example of how this is put into practice is the lecture Ownership of Knowledge, where the problem of plagiarism is explained as part of a longstanding academic discourse. It stresses that universities still perceive themselves in the intellectual tradition of the Enlightenment (16851815), expecting students to be individual contributors to a collective pursuit of knowledge. Particular emphasis is placed on the collaborative nature of research, on the one hand, and the importance of crediting individual work on the other. Accordingly, the practice of referencing is 
framed as a way to build trust between members of the academic community. Discussing the topic along these lines makes students more receptive to hearing messages about avoiding plagiarism. The lecture tackles this by running through examples of original ideas being quoted, paraphrased, summarised and referenced in correct and incorrect ways. This tests students' understanding and helps to draw the boundary more clearly between plagiarism and appropriate use of sources. Moreover, the task of tracking original sources of ideas is firmly established as a holistic academic practice that starts with reading and not an activity that is somehow tagged onto writing an assignment. Framing a delicate topic like plagiarism in this way avoids reprimanding and stigmatising international students in advance. The international ELAs instead take on the role of cultural translators relaying why certain values are held and how these manifest themselves in academic practices.

Another key theme that is culturally embedded is criticality and, just like the concept of plagiarism, it manifests itself in academic practices that are too often taken for granted. Criticality is demonstrated in critical or argumentative writing, an important assessment criterion, especially in the social science degrees so popular with international students. The reason why international students often struggle with this aspect of academic writing has been attributed to different languages operating according to different rhetorical paradigms (Kaplan, 1966). The shift from one paradigm to another has been identified as one of the main challenges international students face (Lu et al., 2016). Moreover, English as a writer-responsible language (Hinds, 1987) poses particular problems to native speakers of Mandarin, a reader-responsible language that relies heavily on contextual knowledge that is shared between writer and reader. When shifting to write in English, Chinese students - the largest sub-group of international students at UK universities (HESA, 2020) - frequently overlook the importance of writer responsibility. This role reversal creates a divergence of academic expectations. While the Anglo-American reader assumes to be guided through an academic text by way of explicit rhetorical features, Chinese student writers hesitate to do so as they expect readers to work out the meaning of the text for themselves and even regard explicit signposting as impolite (Lu et al., 2016). In turn, academic staff tend to interpret the lack of explicit rhetoric that explains the relationship between ideas as a failure in criticality, resulting in low marks and, ultimately, dissatisfied students. At UofG, where over 3,800 students are currently from China, criticality is, therefore, a frequently discussed topic in academic writing classes and one-to-one tutorials.

\section{Ongoing support - Online resources}

The need to understand the concept of criticality and practice critical writing is reflected in students' continuing engagement with academic writing workshops and online resources offered throughout the year. One such online resource is a Moodle course called The UofG Online Guide to Academic Writing. It uses H5P software to create interactive mini-lessons on how to write an academic essay. Students can use the resource to complement LEADS classes or as a self-guided standalone activity. Lessons can be taken chronologically, or individual lesson topics can be selected from a resource index and engaged in as required. The course is divided into seven sections: Getting started, Researching for the Assignment, Planning the Assignment, Writing Critically, Writing Logically, Integrating Evidence and Completing the Writing Cycle. The sections are further subdivided into mini-lessons. The Writing Critically section, for instance, contains five lessons, mainly focusing on academic style, while the Writing Logically section has thirteen mini-lessons, demonstrating how to build logical arguments within different essay sections, paragraphs and on the sentence level.

In its pilot year (2018/19), the course was only accessible to international students, giving the ELAs the opportunity to analyse the specific needs of this cohort. Users of the resource displayed most interest in Descriptive vs Critical Writing, a mini-lesson that compares writing styles, making up $22 \%$ of all engagements with the resource (Moodle Analytics, 2019). This indicates that international students struggle with the concept of criticality and are keen to know how to demonstrate this key skill in their writing. It also corroborates what research on rhetorical diversity has demonstrated all along: that academic writing in another language requires students to use rhetorical strategies they are not familiar with. The mini-lesson first tests students' understanding of descriptive, analytical and critical writing styles, using very short 
excerpts. It then sets a hypothetical question that students are invited to respond to while also reflecting critically on that response. This is followed up with a short exemplary answer that students are encouraged to evaluate. An analysis of the example text highlights the different writing styles employed and identifies its limitations. A second exemplary text provides a critique of the first and students are encouraged once more to analyse its style and the language deployed. By that point the characteristics of the different writing styles are palpable, leaving students with a mini-tool kit to assist them in reading and writing critically. The lesson ends with links to other related lessons in the course.

\section{Ongoing support: One-to-one tutorials}

The academic writing classes and online provision developed by the international ELAs can best be described as teaching Writing across the Curriculum with only limited capacity to convey specific disciplinary conventions. Since the provision is aimed at students from all subject disciplines, the information provided must, by default, be applicable across disciplines. As academic genres vary to a great extent, this is a circle the international ELAs are only able to partially square. With most international students enrolled in social science degrees, the examples used in classes and online lessons are often drawn from these subject areas. This can be to the detriment to students residing in less popular disciplines, such as History of Art or Engineering. The subject focused ELAs working in LEADS are somewhat better equipped to speak to disciplinary conventions because they collaborate more closely with individual colleges. But due to one college consisting of numerous subject disciplines, their practice innately crosses disciplines and they cannot adopt a typical Writing in the Disciplines approach.

While the divergence in writing conventions sometimes comes up in classes, it is in the individual tutorial where these differences can be addressed in any meaningful way as it allows for a dialogue between student and ELA to take place. Inspired by Lillis' (2003) idea of 'talkback not feedback" (p. 204), the international ELAs embrace the dialogical approach, drawing on students' knowledge of genre conventions within their own disciplines. For instance, while a social science essay typically adopts a general-to-specific structure, that might not be an appropriate structure for the same type of assessment in arts or the hard science subjects (Swales \& Feak, 2012). Teasing out what students already know about their discipline and encouraging them to develop their academic literacy is essential in enabling the international ELAs to formulate tailored and appropriate writing advice. This is, of course, not the direct dialogue between subject lecturer and student envisaged by Lillis which would be more effective in developing students' academic literacy in their specific field. But given the structural constraints of the Higher Education sector and large institutions such as the University of Glasgow, the dialogue between ELA and student seems to be a more achievable model. The fact that students book one-to-one tutorials all year around (ca. 1000 per year) and give overwhelmingly positive feedback suggests that this type of dialogue is in demand and appears to be working for students. As a department that develops academic literacies across the curriculum and to some degree within the disciplines, LEADS continuously needs to balance its provision of generic and specific writing advice. The international ELAs embody this challenging balance act most in that they engage with students from all subject disciplines.

\section{Conclusion}

This article has outlined the work of the international Effective Learning Advisers at UofG. It has explained how their role is essential in building bridges for international students and easing their transition into the UK Higher Education context in general and the academic culture at UofG in particular. The article has shown that the international ELAs act as transcultural and cross-disciplinary communicators by focusing on three key areas of provision: open access classes, electronic resources and one-to-one tutorials.

Notwithstanding the important role the international ELAs play at UofG, transition is not only experienced by international students but also by academic staff, both home and international, 
as well as home students (Jindal-Snape et al., 2016). Too often the transitional needs of staff, especially, are not met, leaving them to work out for themselves, through trial and error, what type of teaching methods and assessments work best in an international classroom. In line with Ryan's (2011) transcultural approach to teaching international students, this article contends that it is crucial to enable staff to become aware of the values and assumptions inherent in current practices and help them to reflect on their continued relevance. Such self-awareness would equip staff with the ability to explain current academic practices to students from other academic cultures and, if required, to adapt them to student needs. Ultimately, such awareness and adjustment would contribute to achieving a mutual alignment of academic expectations and, thus, better integration of international students. As Merola et. al (2019) have shown, mutual alignment of expectations and meaningful integration have positive short-term and longterm consequences, leading to higher satisfaction among international students, ensuring their retention and progression and maintaining the appeal of the UK Higher Education sector overall. This article concludes, therefore, that a more holistic approach to internationalisation is necessary, an approach that moves away from the view of international students as deficient and in need of improvement. While learning development certainly helps students to cross the bridge into an unfamiliar academic culture, the transitional needs of staff and home students must also be heeded by offering appropriate training and making changes to the curriculum. The appointment and practice of the international ELAs is an important step in increasing academic alignment but wider institutional change is required to fully bridge the gap. 


\section{References}

Grove, J. (2014, June 19). Tips for detecting and beating plagiarism. Times Higher Education.

Higher Education Statistics Agency. (2020). Where do HE students come from? Higher Education Student Statistics UK. https://www.hesa.ac.uk/data-and-analysis/students/where-from

Hinds, J. (1987). Reader versus writer responsibility: A new typology. In U. Connor \& R. Kaplan (Eds.), Writing across languages: Analysis of L2 text (pp. 141-152). Addison-Wesley Publishing Company.

Jensen, T. W., \& Bay, G. (2019, July 2-4). Non-cheater or taking part in the disciplinary dialogue? The impact of plagiarism software on the development of students' authorial identity [Conference Presentation].10 ${ }^{\text {th }}$ Conference of the European Association for the Teaching of Academic Writing, Gothenburg, Sweden.

Jindal-Snape, D., Rienties, B. (2016). Multi-dimensional transitions of international students to higher education. Routledge.

Kaplan, R. B. (1966). Cultural thought patterns in intercultural education. Language Learning, $16(1-2), 1-20$.

Lillis, T. (2003). Student writing as 'Academic Literacies': Drawing on Bakhtin to move from critique to design. Language and Education, 17(3), 192-207. https://doi.org/10.1080/09500780308666848

Lu Z., Lan L., \& Ottewell, K. (2016). Rhetorical diversity and the implications for teaching academic writing. The Asian Journal of Applied Linguistics, 3(1), 101-113. https://caes.hku.hk/ajal/index.php/ajal/article/download/350/415

McKie, A. (2019, March 20). International students and cheating: How worried should we be? Times Higher Education. https://www.timeshighereducation.com/news/internationalstudents-and-cheating-how-worried-should-we-be

Merola, R. H., Coelen, R. J., \& Hofman, W. H. A. (2019). The role of integration in understanding differences in satisfaction among Chinese, Indian, and South Korean international students. Journal of Studies in International Education, 23(5), 535-553. https://doi.org/10.1177/1028315319861355

Mostrous, A., \& Kenber, B. (2016, January 2). Universities face student cheating crisis. The Times. https://www.thetimes.co.uk/article/universities-face-student-cheating-crisis9jt6ncd9vz7

Pecorari, D. (2008). Academic writing and plagiarism: A linguistic analysis. Continuum.

Quality Assurance Agency Scotland. (2017). International students' transitions into Scottish Higher Education. https://www.enhancementthemes.ac.uk/docs/ethemes/studenttransitions/international-students---transitions-into-scottish-higher-education-ascoping-study.pdf?sfvrsn=58faf681 8

Ryan, J. (2011). Teaching and learning for international students: Towards a transcultural approach. Teachers and Teaching: Theory and Practice, 17(6), 631-648. https://doi.org/10.1080/13540602.2011.625138

Swales, J. M., \& Feak, C. B. (2012). Academic writing for graduate students: Essential tasks and skills. University of Michigan Press. 
University of Glasgow. (2015). Inspiring people - Changing the world: Learning and teaching strategy 2015-2020. https://www.gla.ac.uk/explore/strategy/

University of Glasgow. (2018). Activity report for: The UofG online guide to academic writing. Moodle Analytics.

University of Glasgow. (2019). Student headcount. Planning and Business Intelligence.

Wingate, U., \& Tribble, C. (2012). The best of both worlds? Towards an English for Academic Purposes/Academic Literacies writing pedagogy. Studies in Higher Education, 37(4), 481-495. https://doi.org/10.1080/03075079.2010.525630 